\title{
The Identification of Medical Errors by Family Physicians During Outpatient Visits
}

Nancy C. Elder, MD, MSPH

MaryBeth Vonder Meulen, RN, CCRC

Amy Cassedy, PbD

Department of Family Medicine, University of Cincinnati, Cincinnati, Ohio

Conflicts of interest: none reported

\section{CORRESPONDING AUTHOR}

Nancy C. Elder, MD, MSPH Department of Family Medicine University of Cincinnati PO Box 670582 Cincinnati, OH 45267-0582 eldernc@fammed.uc.edu

\begin{abstract}
BACKGROUND We wanted to describe errors and preventable adverse events identified by family physicians during the office-based clinical encounter and to determine the physicians' perception of patient harm resulting from these events.
\end{abstract}

METHOD We sampled Cincinnati area family physicians representing different practice locations and demographics. After each clinical encounter, physicians completed a form identifying process errors and preventable adverse events. Brief interviews were held with physicians to ascertain their perceptions of harm or potential harm to the patient.

RESULTS Fifteen physicians in 7 practices completed forms for 351 outpatient visits. Errors and preventable adverse events were identified in $24 \%$ of these visits. There was wide variation in how often individual physicians identified errors (3\% to $60 \%$ of visits). Office administration errors were most frequently noted. Harm was believe to have occurred as a result of $24 \%$ of the errors, and was a potential in another $70 \%$. Although most harm was believed to be minor, there was disagreement as to whether to include emotional discomfort and wasted time as patient harm.

CONCLUSIONS Family physicians identify errors and preventable adverse events frequently during patient visits, but there is variation in how some error categories are interpreted and how harm is defined.

Ann Fam Med 2004;2:125-129. DOI: 10.1370/afm.16.

\section{INTRODUCTION}

$\mathrm{T}$ he role of medical errors and adverse events as important factors in the health outcomes of patients is well known, at least for hospitalized patients. ${ }^{1,2}$ Identifying adverse events and attributing cause to error, however, is difficult. ${ }^{3.5}$ Most of the medical care in the United States occurs not in the hospital but in the outpatient primary care setting, ${ }^{6}$ where the role of medical errors is even less clear. Until now outpatient studies have collected retrospective physician-generated reports of errors they have made ${ }^{7}$ or noted in their practices. ${ }^{8.10} \mathrm{~A}$ few studies have examined specific areas of potential error, such as physician-patient communication, ${ }^{11}$ specialist-primary care communication, ${ }^{12}$ or incident report claims. ${ }^{13}$ When combined, these studies begin to document the full breadth of errors recognized primarily by physicians, but they offer minimal information on incidence or severity. ${ }^{14} \mathrm{~A}$ more accurate assessment of the incidence and severity of errors and preventable adverse events in primary care is necessary to develop successful interventions to improve patient safety.

The purpose of this study was to have physicians identify prospectively those errors and preventable adverse events that occur during office-based clinical encounters and to assess the physicians' perceptions of harm from these errors. This effort is a preliminary step in defining the incidence of medical errors and their associated harm in outpatient primary care. 
Figure 1. Physician survey form for indicating types of medical errors and preventable adverse events encountered during office visits.

Patient ID:

Physician ID:

Office ID:

Date:

Pt. Gender: M F

Did you discover any of the following had occurred or did they occur now with this patient due to a preventable cause from the health care system?

\begin{tabular}{|l|l|l|l|}
\hline DIAGNOSIS & During workup of symptoms & During preventive screening & Other/uncertain \\
\hline A misdiagnosis & & & \\
\hline A delayed diagnosis & & & \\
\hline A missed diagnosis & & & \\
\hline
\end{tabular}

\begin{tabular}{|l|l|l|l|l|}
\hline MANAGEMENT AND TREATMENT & Drug or pharmaceutical & $\begin{array}{l}\text { Dose of a drug } \\
\text { or pharmaceutical }\end{array}$ & $\begin{array}{l}\text { Other therapy, } \\
\text { treatment or procedure }\end{array}$ & Preventive services \\
\hline Incorrect or inappropriate & & & & \\
\hline Delayed & & $X X X X X X X X X X X$ & & \\
\hline Omitted or forgotten & & $X X X X X X X X X X X$ & & \\
\hline Procedural complication & $X X X X X X X X X X X$ & $X X X X X X X X X X X$ & & \\
\hline
\end{tabular}

Did any of the following occur today, or did you discover they had occurred in the past with this patient?

\begin{tabular}{|c|c|c|c|c|c|c|}
\hline PHYSICIANS AND STAFF & $\begin{array}{l}\text { Clinical judgment } \\
\text { problem }\end{array}$ & $\begin{array}{l}\text { Procedural skill } \\
\text { problem }\end{array}$ & $\begin{array}{l}\text { Communication } \\
\text { problem with } \\
\text { patient }\end{array}$ & $\begin{array}{l}\text { Felt or appeared } \\
\text { rushed or hurried }\end{array}$ & $\begin{array}{l}\text { Felt or appeared } \\
\text { distracted }\end{array}$ & $\begin{array}{l}\text { Interrupted } \\
\text { during encounter }\end{array}$ \\
\hline \multicolumn{7}{|l|}{ Physician (self) } \\
\hline \multicolumn{7}{|l|}{$\begin{array}{l}\text { Physician (others incl. partners, } \\
\text { consultants) }\end{array}$} \\
\hline \multicolumn{7}{|l|}{ Other staff / providers (in office) } \\
\hline $\begin{array}{l}\text { Other staff / providers (outside } \\
\text { of office) }\end{array}$ & & & & & & \\
\hline
\end{tabular}

\begin{tabular}{|l|l|l|l|l|}
\hline CHARTING & Missing from chart & In wrong patient's chart & In wrong place in the chart & $\begin{array}{l}\text { Wrong information } \\
\text { in the chart }\end{array}$ \\
\hline Lab or X-ray report & & & & \\
\hline Insurance information & & & & \\
\hline Dictation or chart note & & & & \\
\hline Medicine or problem list & & & & \\
\hline Consultants note or letter & & & & \\
\hline Hospital records & & & \\
\hline
\end{tabular}

\begin{tabular}{|l|l|l|l|l|}
\hline & $\begin{array}{l}\text { Missing or } \\
\text { unavailable } \\
\text { when needed }\end{array}$ & Broken & Untrained & Unused \\
\hline Entire medical chart & & $\mathrm{XXXX}$ & $\mathrm{XXXXX}$ & $\mathrm{XXXX}$ \\
\hline Forms or paperwork & & $\mathrm{XXXX}$ & $\mathrm{XXXXX}$ & \\
\hline Equipment & & & $\mathrm{XXXXX}$ & \\
\hline $\begin{array}{l}\text { Staff, including nursing } \\
\text { and clerical }\end{array}$ & & $\mathrm{XXXX}$ & & $\mathrm{XXXX}$ \\
\hline Tickler/reminder system & & & $\mathrm{XXXXX}$ & \\
\hline
\end{tabular}

Was there a problem not listed above discovered today?

Were NO problems or errors discovered today?

\begin{tabular}{|l|l|}
\hline INVESTIGATIONS AND FLOW & $\begin{array}{c}\text { Problem occurred } \\
\text { or was discovered }\end{array}$ \\
\hline $\begin{array}{c}\text { Incorrect lab or x-ray done } \\
\text { or ordered }\end{array}$ & \\
\hline $\begin{array}{c}\text { Delay in getting lab or } \\
\text { x-ray done or results }\end{array}$ & \\
\hline $\begin{array}{c}\text { Referral problems (incl. } \\
\text { communication) }\end{array}$ & \\
\hline Appointment problem & \\
\hline Triage problem & \\
\hline Phone message problem & \\
\hline
\end{tabular}




\section{METHODS}

\section{Sample}

Two to 4 physicians in each of 9 family practice offices in the greater Cincinnati area were approached to take part in a study "of the errors and problems that seem to occur almost daily in practice." These offices were purposefully chosen to offer a variety of urban, suburban, and rural locations, as well as large and small practice sizes, and to include both men and women physicians. For convenience, these offices included faculty and residency practices, family medicine clerkship preceptor practices, and practices that employed former residents or students. For unknown reasons, the 2 largest practices elected not to participate, and 4 physicians at participating practices chose not to participate.

\section{Data Collection}

We designed a form that listed the types of medical errors and preventable adverse events family physicians had reported in published studies (Figure 1). 7,8,10,13 From previous work ${ }^{14}$ we had devised a classification of these errors and preventable adverse events that was applicable to practicing family physicians. We adapted the classification to include those errors that were likely to be identified during outpatient visits.

Physicians received individual training from the principal investigator (NCE) on completion of the survey form. Forms were distributed for consecutive patient visits in half-day sessions. The research assistant attached the 1-page form to each patient chart, and the physician completed the form with check marks immediately after leaving the examination room. The physician could indicate on the form whether any of the items listed had occurred during the encounter or were discovered during the encounter. The form was not designed to detect whether a decision or action made by the physician that day was later found to be in error.

Each participating physician completed the forms until 20 to 40 patient visits had been assessed. Because there are no existing data on which to estimate the number of patient visits to assess, we choose this number so we could collect patient visit data for at least 3 half-day sessions and avoid being too intrusive into the physician's practice.

At the end of each half-day clinical session, the research assistant interviewed each physician about identified errors. For each error indicated, physicians were asked to describe what happened and to make a judgment as to whether any harm came to the patient or whether potential harm was possible. Harm was not defined for the physicians, and they were asked to describe the perceived harm or potential harm. Depending on the number of errors to be discussed, interviews were either recorded on an audiotape or notes were taken by the research assistant.

\section{Data Analysis}

Data were entered into a data set, and descriptive statistics were performed using SAS System for Windows, release 8.02 (SAS Institute, Cary, NC). Interview tapes and notes were reviewed by both the investigator and the research assistant, and physician assessments and descriptions of harm were collected. The errors were grouped according to the existing classification system. ${ }^{14}$ Harm descriptions were listed verbatim, and using immersion or crystallization ${ }^{15}$ and ongoing discussion among the researchers, the harm descriptions were grouped into categories.

\section{RESULTS}

Fifteen family physicians in 7 offices in diverse geographic locations participated in the study. There were 4 urban practices with 6 participating physicians, 2 suburban practices with 5 participating physicians, and 1 rural practice with 4 participating physicians. Seven of the 15 physicians were women. The physicians ranged in age from 31 to 52 years. No large (more than 15) physician practices participated, other than the 2 residency teaching practices. None of the practices had an electronic medical record system. At the residency practices, only faculty physicians participated.

These 15 physicians filled out forms for 351 patient visits (range 18 to 31 per physician). They identified 117 errors or preventable adverse events during 83 patient visits $(23.6 \%)$; only 1 error was identified during 61 patient visits, and 2 or more errors were identified during 22 patient visits. Among the 4 a priori groupings (Table 1$)^{14}$ the most frequently identified errors were office administration errors. There was a wide range among physicians in the frequency with which they identified these errors. Individual physicians noted errors or events in $3.2 \%$ to $60 \%$ of their patient visits. Between office practices, the range was still wide, $9.7 \%$ to $60 \%$. Most of the variability was seen in the category we described as physician-related errors. Women physicians identified errors in $26.3 \%$ of their encounters, whereas men physicians did so in $21.2 \%$ $(P=.26$ by chi-square $)$

Physicians responded to questions about harm for 76 of the 83 patient visits in which they indicated errors. For these patients, they estimated that harm had occurred for 18 patients $(23.7 \%)$ and that potential harm was present for 53 patients $(69.7 \%)$. The actual harm identified by physicians was believed to be minor. Examples included physical discomfort, a mild adverse drug reaction, moderate physical injury from a procedure, and 


\begin{tabular}{|c|c|c|}
\hline Classification & Examples & $\begin{array}{l}\text { Patient Visits } \\
\text { With Errors } \\
\text { No. (\%) }\end{array}$ \\
\hline Office administration errors & & $57(16.5)$ \\
\hline Charting & $\begin{array}{l}\text { Any part of chart is not present, is in the wrong } \\
\text { place, entire chart is missing }\end{array}$ & $37(10.5)$ \\
\hline General office administration & $\begin{array}{l}\text { Staffing problems, missing or incorrect forms or } \\
\text { paperwork, laboratory or radiograph process- } \\
\text { ing errors }\end{array}$ & $21(6.0)$ \\
\hline Physician-related errors & $\begin{array}{l}\text { Skill problems, time management problems } \\
\text { (interrupted, feeling rushed) }\end{array}$ & $28(8.0)$ \\
\hline Patient communication errors & $\begin{array}{l}\text { Problems communicating with patient by physi- } \\
\text { cian, staff, or other physicians; appointment } \\
\text { and triage errors }\end{array}$ & $16(4.5)$ \\
\hline Preventable adverse events & $\begin{array}{l}\text { Missed diagnosis, misdiagnosis, delayed treat- } \\
\text { ment, incorrect treatment }\end{array}$ & $15(4.3)$ \\
\hline
\end{tabular}

progression of disease. The most common descriptions of harm by far were increased emotional distress and wasted time for the patient. Not all physicians considered wasted time to be harm; some merely mentioned it as a consequence of the identified error but described it as a nuisance or hassle, rather than harm.

The types of potential harm assessed by the physicians included the development of a preventable disease, pain or physical distress, progression of disease, drug-drug interactions, infection, and poor outcomes from a procedure, as well as increased emotional distress and wasted time for the patient. A common physician response was, "in this case there was no harm, but with this same situation and another patient, there could have been harm."

\section{DISCUSSION}

Physicians in these practices identified errors or preventable adverse events in almost one quarter of their clinical encounters. There was, however, great variation in the rate and types of errors identified by physicians in their practices, which is an indication of the challenge in studying error incidence and severity. Even when errors were specific and devised from previous physician reports, as in this study, there was still room for interpretation by the physician participants. For some categories, the decision of whether an error occurred that was easy to make, such as when, for example, the patient's entire chart was missing during the visit. For other categories, however, especially for "physician-related errors," more variation was found. Some physicians acknowledged being rushed, distracted, and interrupted more readily than did others. As physicians and other health professionals are called upon to report medical errors and adverse events, this lack of standardization and agreement needs to be considered.

The concept of harm and the confusion surrounding harm in outpatient primary care are also important issues. Among the physicians in our study, there was no agreement about where nuisance ends and harm begins. In other disciplines, similar dilemmas exist. For example, in criminology the interpretation of the words "wrong" and "harm" shows that some respondents perceive degrees of harm, whereas others perceive only dichotomous categories of harm and no harm. ${ }^{16}$

Clarifying definitions for harm, refining a typology of errors, and estimating incidence are important tasks for future medical errors research in primary care. Multiple authors have proposed models of medical errors which show that latent, ${ }^{17}$ process ${ }_{1}^{14}$ or trickle-down errors $^{18}$ are necessary factors in the development of preventable adverse events and patient harm. Most of the time, as in this study, process errors occur and lead to no harm, because they are picked up by safety features in the primary care health system. When preventable adverse events do occur, and patients are harmed, a root cause analysis ${ }^{7,19-21}$ of the factors which lead to the harm often shows that process or latent errors are causally related..$^{7,14}$

This study has a number of limitations. The geographic location was small; only 7 practices participated, and a limited number of patient encounters were surveyed. The ability to generalize from these data to other family physicians, especially those in large practices and offices with an electronic medical record system, is limited. Errors were captured only during the patient encounter, leaving errors related to telephone calls, triage, follow-up, and other visits minimally detected. Even so, the office visit probably offers opportunities to capture the largest number of errors because of the collation and summary of information that occur during the visit. Some physicians, fearful of litigation and shame, 22,23 might have shied away from identifying or acknowledging the more obvious errors, such as delayed or missed diagnoses or inappropriate therapies.

Errors are occurring in family physicians offices. ${ }^{10,14}$ This study shows that a volunteer sample of family physicians found errors and identified preventable adverse events in $23.6 \%$ of their patient visits, and they estimated that $23.7 \%$ of those errors and events led 
to minor patient harm. To understand fully the scope of medical errors in primary care, input is also needed from other health care workers and from patients. ${ }^{24}$ As further studies are done, interventions can be designed to address the most common and most serious errors in primary care.

To read commentaries or to post a response to this article, see it online at http://www.annfammed.org/cgi/content/full/2/2/125.

Key words: Medical errors; diagnostic errors; medication errors; patient safety; delivery of health care; health services research

Submitted November 22, 2002; submitted, revised, March 5, 2003; accepted March 26, 2003.

Versions of this paper were presented at the North American Primary Care Research Group, November 18, 2002, New Orleans, La.

Funding support: This paper was supported, in part, by a research stimulation grant of the American Academy of Family Physicians/American Academy of Family Physicians Foundation.

\section{References}

1. Kohn L, Corrigan J, Donaldson M. To Err is Human: Building a Safer Health System. Washington, DC: National Academy Press; 1999.

2. Committee on Health Care Quality in America. Crossing the Quality Chasm. A New Health System for the 21st Century. Washington, DC: National Academy Press; 2001.

3. Leape LL. Institute of Medicine medical error figures are not exaggerated. JAMA. 2000;284:95-97.

4. Hayward R, Hofer T. Estimating hospital deaths due to medical errors: preventability is in the eye of the reviewer. JAMA. 2001;286: 415-420.

5. McDonald CJ, Weiner M, Hui SL. Deaths due to medical errors are exaggerated in Institute of Medicine report. JAMA. 2000;284:93-95.

6. Green L, Fryer G, Yawn B, Lanier D, Dovey S. The ecology of medical care revisited. N Engl J Med. 2001;344:2021-2025.

7. Ely JW, Levinson W, Elder NC, Mainous AG III, Vinson DC. Perceived causes of family physicians' errors. J Fam Pract. 1995;40:337-344.

8. Bhasale AL, Miller GC, Reid S, Britt HC. Analysing potential harm in Australian general practice; an incident-monitoring study. Med J Aust. 1998;169:73-76.
9. Makeham MA, Dovey SM, County M, Kidd MR. An international taxonomy for errors in general practice: a pilot study. Med J Aust. 2002;177:68-72.

10. Dovey SM, Meyers DS, Phillips RL, et al. A preliminary taxonomy of medical errors in family practice. Qual Saf Health Care. 2002;11:233238.

11. Britten N, Stevenson FA, Barry CA, Barber N, Bradley CP. Misunderstandings in prescribing decisions in general practice: qualitative study. BMJ. 2000;320:484-488.

12. Gandhi TK, Sittig DF, Franklin M, Sussman AJ, Fairchild DG, Bates DW. Communication breakdown in the outpatient referral process. J Gen Int Med. 2000;15:626-631.

13. Fischer G, Fetters MD, Munro AP, Goldman EB. Adverse events in primary care identified from a risk-management database. J Fam Pract. 1997;45:40-46.

14. Elder N, Dovey S. A classification of medical errors and preventable adverse events in primary care: a synthesis of the literature. J Fam Pract. 2002;51:927-932.

15. Crabtree B, Miller W. Doing Qualitative Research. 2nd ed. Thousand Oaks, Calif: Sage Publications; 1999.

16. Warr M. What is the perceived seriousness of crimes? Criminology. 1989;27:795-819.

17. Reason J. Human error: models and management. BMJ. 2000;320: 768-770.

18. Toxic cascades: a comprehensive way to think about medical errors. Am Fam Phys. 2000;62:848.

19. Bhasale A. The wrong diagnosis: identifying causes of potentially adverse events in general practice using incident monitoring. Fam Pract. 1998;15:308-318.

20. Dean B, Schachter M, Vincent C, Barber N. Causes of prescribing errors in hospital inpatients: a prospective study. Lancet. 2002;359: 1373-1378.

21. McNutt RA, Abrams RI. A model of medical error based on a model of disease: interactions between adverse events, failures, and their errors. Qual Manag Health Care. 2002;10:23-28.

22. Davidoff F. Shame: the elephant in the room. BMJ. 2002;324:623-624.

23. Goldberg RM, Kuhn G, Andrew LB, Thomas HA, Jr. Coping with medical mistakes and errors in judgment. Ann Emerg Med. 2002;39: 287-292.

24. Kuzel A, Woolf S, Engel J, et al. Characterizing medical error in primary care settings. Paper presented at: North American Primary Care Research Group 29th Annual Meeting; 2001; Halifax, Nova Scotia. 